\title{
LAS ACCIONES CAMBIARIAS Y EXTRACAMBIARIAS DE LOS TÍTULOS VALORES
}

EXCHANGEABLE EXCHANGE
SHARES OF SECURITIES

ENRIQUe VigiL Oliveros* DiANA UCHUYPUMA TUPIA**

* Magister en Derecho Tributario y Fiscalidad Internacional por la Universidad de San Martín de Porres.Giurista D Impresa por la Universitá degli Studi di Bologna-Italia-Post Grado en Derechos Humanos, Arbitraje Internacional, Comercio Exterior y Medio Ambiente en la American University-Washington DC-Estados Unidos. Catedrático de los cursos de Derecho Empresarial, Derecho Corporativo y Títulos Valores de la Universidad Particular de San Martín de Porres. Catedrático nombrado en los cursos de Introducción al Derecho y Sociedades I en la Universidad Femenina del Sagrado Corazón.

** Estudiante del Ciclo XII de la carrera de derecho de la Universidad Femenina de Sagrado Corazón

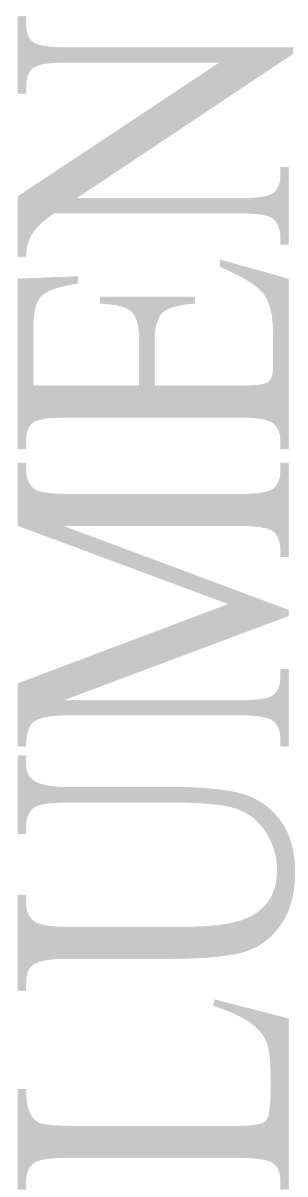




\title{
LAS ACCIONES CAMBIARIAS Y EXTRACAMBIARIAS DE LOS TÍTULOS VALORES
}

\author{
EXCHANGEABLE EXCHANGE SHARES OF SECURITIES
}

\author{
Enrique Vigil Oliveros \\ Diana Uchuypuma Tupia
}

\begin{abstract}
RESUMEN
El presente informe tiene como objetivo analizar las acciones cambiarias y extracambiarias, las cuales derivan de un título valor, esto se realiza con la finalidad de conocer qué tipos de acciones puede ejercer el tenedor en caso de incumplimiento. Todo título valor que contenga la relación cambial podrá ir por el Proceso Único de Ejecución, en caso no lo posea, irá por otra vía judicial. En otras palabras, el tenedor nunca perderá la facultad de reclamar la obligación primitiva, sino que dependerá a qué vía le corresponde ir, ya que nuestra legislación favorece al acreedor legítimo de cualquier abuso de derecho.
\end{abstract}

\section{PALABRAS CLAVE}

Título valor, Acción Cambiaria, acción directa, acción de regreso, Acciones Extracambiarias, acción de ulterior regreso, acción causal, acción de enriquecimiento sin causa y protesto.

\begin{abstract}
The purpose of this report is to analyze the exchange and extra-exchange actions, which derive from a security, this is done with the purpose of knowing what types of shares the holder can exercise in case of default. Any security title that contains the exchange relationship may go through the Single Execution Process, if it does not possess it, it will go through another judicial route. In other words, the holder will never lose the power to claim the primitive obligation, but it will depend on which way he should go, since our legislation favors the legitimate creditor of any abuse of right.
\end{abstract}

\section{KEY WORDS}

Title value, Exchange Action, direct action, return action, Extra Exchange Actions, subsequent return action, causal action, enrichment action without cause and protest.

\section{INTRODUCCIÓN}

Los títulos valores son documentos de carácter patrimonial, destinados a la circulación, este concepto también lo recoge la Nueva Ley General de Títulos Valores (Ley N²7287), aunque incorpora nuevas concepciones, como los títulos desmaterializados, ya que el documento no solo será en soporte físico, sino también electrónico, donde encontramos a las acciones y bonos, esto gracias a los avances de las telecomunicaciones, ya que el derecho es dinámico y debe regular la realidad de la sociedad.

En ese mismo sentido, los títulos cartulares poseen acciones cambiarias, las cuales dan el derecho al tenedor para llevar a cabo el cobro del importe contenido en el título valor, en otras palabras, es una figura que reviste al acreedor para ir en vía judicial a reclamar su derecho, en caso no haya cumplido el obligado.

Según la doctrina y la Ley $\mathrm{N}^{\circ} 27287$ los tipos de acciones cambiarias son: directa, de regreso y de ulterior regreso. Estas derivaciones responden a la complejidad y al dinamismo que posee esta 
figura, ya que en un título valor, no solo interviene el acreedor y deudor principal, sino que también pueden encontrarse avalistas, fiadores y nuevos tenedores.

En ese mismo sentido, se debe señalar que la acción cambiaria se puede perder, ya sea porque el tenedor perjudicó el título valor, no lo protestó en el plazo correspondiente, o no cumplió con los requisitos formales que establece la Nueva Ley General de Títulos Valores, al configurarse estos supuestos, el tenedor tendrá la posibilidad de exigir la obligación, pero no del título valor, sino por la relación causal o por el enriquecimiento sin causa.

Las acciones extracambiarias se configuran cuando el tenedor pierde la relación cambial, pero no se puede aplicar el abuso del derecho, por esta razón se le da otra vía al tenedor para reclamar la obligación primitiva.

\section{NOCIÓN DE TÍTULO VALOR}

"Es un documento que contiene o representa un derecho patrimonial destinado a la circulación comercial y que cumple los requisitos formales y esenciales que establece la Nueva Ley de Títulos Valores".

Como podemos apreciar, el título valor responde a la naturaleza cartular, puesto que es un documento que representa una obligación de pago que debe cumplir el deudor. Además, que debe estar destinado a la circulación comercial, esto quiere decir, que se debe evitar como dé lugar el tráfico comercial.

"En términos generales la doctrina reconoce en el título valor una promesa unilateral (del deudor) de efectuar una prestación; encierra la asunción de una obligación, vinculante e irrevocable, propia de un negocio unilateral. Es un documento representativo de un derecho, en tanto que el título se convierte en el derecho mismo y también constituye una declaración de voluntad emitida por alguien, de donde se infiere que no solamente es representativo en sí, sino también constitutivo y dispositivo de un derecho".

En el título valor se reconoce un derecho, el cual es el de exigir el pago de la obligación, con tan solo mostrar el documento, esto quiere decir, que el tenedor no debe probar nada en particular.

En ese mismo orden de ideas, se debe señalar que la presente figura tiene un carácter irrevocable y transmisible, ya que una vez firmada el título cambiario, este produce todos sus efectos, además que puede transmitirse mediante endoso.

\section{DEFINICIÓN DE ACCIÓN CAMBIARIA}

En opinión de Baccario Castañeira, citado por la acción cambiaria “... es el poder jurídico que se tiene, para acudir al órgano jurisdiccional, a los efectos de obtener el cumplimiento de la obligación asumida en un título cambiario”. Dicho autor precisa que “... la acción es cambiaria cuando se trata de una de las que puede ejercitar el portador de un título cambiario, contra los obligados al pago, sobre la base y en razón de dicho título". (Castañeira, 1980, pág. 166)

Como podemos apreciar en el párrafo anterior, la acción cambiaria es la facultad que tiene el tenedor para exigir al deudor el pago de la obligación contenida en un título valor a través de la vía judicial, esto quiere decir que el acreedor del título podrá pedir tutela jurisdiccional (intervención del estado) para ser exigible el monto consignado en el título cambiario.

Conociendo los productos y servicios financieros, Instituto de formación bancaria, concepto de título valor. Disponible en: https://es.scribd.com/document/350019786/Los-Títulos-Valores-PDF.

2 Hernando Montoya Alberti, Nueva Ley de Títulos Valores, comentarios. Gaceta Jurídica, pág. 6. 
En ese mismo sentido, se debe señalar que la acción cambiaria tiene dos connotaciones: una sustancial y la otra procesal. La primera está vinculada a la pretensión cambiaria, esto quiere decir el derecho sustancial del tenedor de obtener el pago; mientras que la segunda responde a la intervención del estado, quien tutelará la pretensión jurídica material interpuesta por el tenedor.

En ese mismo orden de ideas, mientras el tenedor mantenga la relación cambiaria, podrá exigir la obligación cartular en el Proceso Único de Ejecución, de lo contrario, tendrá que acudir a otra vía judicial.

En el Perú esta figura es recogida en la Nueva Ley General de Títulos Valores en los artículos $90,91,92,93$ y 94 .

\section{TIPOS DE ACCIONES CAMBIARIAS}

Según la doctrina existen tres tipos de acciones cambiarias: la acción directa, la acción de regreso y la acción de ulterior regreso.

\subsection{ACCIÓN CAMBIARIA DIRECTA}

Según Legón "la acción cambiaria directa es la que se ejercita contra el aceptante y sus avalistas". (Legon, 1981, pág. 201).

En ese mismo sentido, se debe señalar que esta acción la ejerce el tenedor del título valor hacia el aceptante (o librador) y sus avalistas. La acción cambiaria directa es aquella que reviste de legitimidad el reclamo del acreedor hacia su deudor y avalista.

Maisch Von Humboldt afirma que "la acción cambiaria directa es la facultad concedida al tenedor legítimo de la cambial (acreedor cambiario) para interponer un proceso ejecutivo en contra del aceptante (deudor cambiario y/o su avalista) para conseguir la prestación debida, realizando los bienes del deudor" (Humboldt, 1968, pág. 166)

La acción cambiaria directa responde a la relación directa entre acreedor, deudor y/o avalista, ya que la relación cambiaria nació con estos tres intervinientes, y es por esta razón del nombre.

En ese orden de ideas, la acción cambial directa es aquella pretensión del acreedor cambiario de hacer exigible el cobro del monto consignado en el título a su deudor principal o avalista, quienes responderán de manera solidaria, esto quiere decir que el tenedor podrá exigir el pago a cualquiera de ellos, de manera indistinta.

Sobre el particular, Supino y De Semo apuntan que:

"Si la acción directa se ejercita por el portador (último endosatario), contra el aceptante o su avalista o contra ambos, comprende: $1^{\circ}$ el monto de la letra no pagada, con los intereses, en caso de haberse indicado; $2^{\circ}$ los intereses a partir del vencimiento, según la tasa indicada en el titulo [...], o a falta de ella, según la tasa legal; $3^{\circ}$ los gastos del protesto, avisos dados, etc. Estas son todas consecuencias de la falta de pago por parte del aceptante, y es justo ponerlas a su cargo [...].

En cambio si la acción directa se ejercita por un obligado en regreso (aunque sea el librador), que pagó la letra, tendrá por objeto: $1^{\circ}$ la suma íntegra desembolsada; $2^{\circ}$ los intereses sobre esa suma de acuerdo a la tasa indicada en el título [...] o a falta de ella, según la tasa legal al día del desembolso de la suma cambiaria por parte del obligado en regreso; $3^{\circ}$ los gastos efectuados..." (Supino \& De Semo, 1950, págs. 560-561). 
Al respecto, se debe señalar que hay dos formas de ejercitar la acción directa: por el portador y el obligado de regreso. La primera es realizada por el ultimo endosatario contra el aceptante y/o avalista, lo que podrá reclamar es el monto de la letra no pagada con los intereses respectivos; los intereses a partir del vencimiento, según la tasa indicada en el título, en caso no se haya estipulado, se aplicará el interés legal, entre otros.

\subsection{ACCIÓN DE REGRESO}

Según Zegarra Guzmán "se denomina acción cambiaria de regreso la que concede contra los responsables subsidiarios del pago de la cambial, girador, endosante, así como los avalistas de estos y aquellos". (Guzmán, 1992, pág. 20)

Del párrafo anterior se desprende que la acción de regreso va dirigida contra los responsables subsidiarios, esto quiere decir, a todos los intervinientes del título valor, con excepción del acreedor y/o deudor principal, ya que se configura la responsabilidad solidaria.

[...] "El regreso no consiste sino en el uso que hace el tenedor de la letra de la garantía que asumen el librador, el avalista y los endosantes en virtud de sus respectivas promesas indirectas de pago; y su nombre proviene sencillamente de que, al dirigirse el tenedor de la letra contra el librador, los endosantes, o los avalistas, procede en sentido inverso al curso normal de aquella, volviendo o regresando sobre personas que le preceden en la tenencia y firma del documento..." (Uría, 1990, pág. 862)

En ese mismo sentido, se puede afirmar que esta acción es ejercida por el tenedor del título cambiario contra el librador, el avalista y los endosantes, ya que, al firmar el documento, los intervinientes realizaron promesas indirectas de pago, por lo cual, deberán reembolsar al tenedor por el pago de la obligación. Esta vía se aplica en sentido inverso, esto quiere decir, que se regresa sobre las personas que anteriormente tenían y firmaron el título valor, con excepción del acreedor y/o deudor principal.

\subsection{ACCIÓN DE ULTERIOR REGRESO}

Según Bonfanti y Garrone "la acción de ulterior regreso (o de reembolso) es una mera forma o modalidad de la más genérica acción de regreso. Se reserva esa designación para el obligado de regreso que pagó y acciona a su vez contra los obligados que le preceden en la cadena cambiaria". (Bonfanti \& Garrone, 1981, pág. 486)

La presente acción también es denominada reembolso, ya que quien paga la obligación podrá ejercitar repetición contra los obligados que lo preceden en el nexo cambiario, los cuales no quedan liberados. También debemos señalar que la acción de ulterior regreso es dependiente y se da en consecuencia de la acción de regreso, esto quiere decir que para que exista la presente acción, se configurará primero el derecho de regreso. Además, que se podrá repetir con cualquiera de los intervinientes del título valor, incluso el deudor y/o acreedor principal, siempre y cuando se encuentren en la cadena cambiaria.

\section{REQUISITOS PARA EJERCER LAS ACCIONES CAMBIARIAS}

En el artículo 91 de la nueva Ley General de Títulos Valores, menciona cuales son los requisitos para ejercer las acciones cambiarias, las cuales son:

- Que los títulos valores hayan sido protestados

- Si se trata de títulos valores no sujetos a protesto, pero si a una formalidad sustitutoria de este, haber obtenido constancia de la falta de cumplimiento de la obligación. 
- Tratándose de títulos valores no sujetos a protesto, cuyo plazo está vencido o resulta exigible la obligación según texto del documento, o de la constancia de inscripción y titularidad que expida la Institución de Compensación y Liquidación de Valores, tratándose de valores anotados en cuenta. ${ }^{3}$

Al respecto, analizaremos la primera premisa, que los títulos hayan sido protestados, el cual responde a un acto jurídico mediante el cual se hace constar fehacientemente que el deudor se niega a cumplir con el pago de la obligación del título valor. El protesto es un medio de prueba para el tenedor, ya que al encontrarse insatisfecho con el accionar del deudor, irá por la vía ejecutiva para exigir el cumplimiento, esta figura reviste al título cambiario de mérito ejecutivo.

En otro orden de ideas, el segundo supuesto establece que los títulos valores no sujetos a protesto, deberán tener otra formalidad con la finalidad de acreditar el incumplimiento de la obligación, el cual será una constancia, y así poseer el mérito ejecutivo.

Por otro lado, la tercera premisa responde a los títulos valores no sujetos a protesto, ni a formalidad sustitutoria, en este supuesto el acreedor deberá comunicar a la Cámara de Comercio Provincial para la inscripción en el registro de protestos, con la finalidad de ejercitar las acciones cambiarias derivadas del título cartular.

Al momento de ir a la vía judicial el legítimo tenedor deberá acompañar a la demanda la constancia de haber informado a la Cámara de Comercio, de lo contrario, será declarado improcedente, al no tener mérito ejecutivo.

Cabe recordar que mientras el título valor tenga la acción cambiaria, el tenedor podrá exigir el cumplimiento por el Proceso Único de Ejecución, ya que se evalua el mérito ejecutivo.

\section{PRESCRIPCIÓN DE LAS ACCIONES CAMBIARIAS}

Según la Nueva Ley General de Títulos Valores las acciones prescriben cuando:

\section{Artículo 96}

"96.1 Las acciones cambiarias derivadas de los títulos valores, prescriben:

a) A los tres años, a partir de la fecha de su respectivo vencimiento, la acción directa contra el obligado principal y/o sus garantes;

b) Al año, a partir de la fecha de su vencimiento, la acción de regreso contra los obligados solidarios y/o garantes de éstos;

c) A los seis meses, a partir de la fecha de pago en vía de regreso, la acción de ulterior regreso contra los obligados y/o garantes de éstos, anteriores a quien lo ejercita. Dentro de este mismo plazo debe ejercitarse la acción de repetición que corresponda al garante del obligado principal contra éste.

96.2 En el caso de los Cheques, los plazos de prescripción señalados en los incisos a) y b) se computan a partir del último día del plazo de presentación a cobro señalado en esta Ley; y, en el caso de los demás títulos valores con vencimiento a la vista, el cómputo se hará a partir del día de su presentación a cobro o, de no haberse dejado constancia de ello, a partir del día de su respectivo protesto o de la formalidad sustitutoria; $y$, de no estar sujeto a ello a partir del último día para su presentación al pago conforme a ley o del señalado para ello en el mismo título.

3 Hernando Montoya Alberti (2000). Nueva Ley de Títulos Valores, comentarios. Pág. 332. 
96.3 Sin perjuicio de lo señalado en el segundo párrafo del Artículo 95, los plazos de prescripción establecidos en el presente artículo son perentorios y no admiten interrupción, ni suspensión. El reconocimiento judicial del título valor vencido no interrumpe los plazos de prescripción señalados en el presente artículo para el ejercicio de las acciones cambiarias derivadas de él."4

Al respecto es necesario señalar qué plazo le corresponde a cada tipo de acción cambiaria, la acción cambiaria directa es 3 años, la acción de regreso es 1 año y la acción de ulterior regreso es de 6 meses.

En ese mismo sentido, la prescripción hace referencia a la pérdida de las acciones cambiarias que emergen de cualquier título valor, ya sea una letra de cambio, un pagare, un cheque, entre otros.

Cabe mencionar que la prescripción cambiaria es vista como la facultad que tiene el deudor para oponer al acreedor, por su tardía acción en el tiempo, este siempre operará como excepción. Esta figura causa la extinción general de las obligaciones cambiarias, y como algo que extingue todos los derechos inherentes a la letra, en rigor no tiene por sí sola o sin más ese efecto extintivo.

Aquí se aplicará la diligencia del tenedor, pues de lo contrario, el deudor aplicará la excepción de prescripción por la vía judicial, en otras palabras, se pierde la cambial y el mérito ejecutivo.

\section{ACCIONES EXTRACAMBIARIAS}

Según Jaureguiberry "se denomina acciones extracambiarias las que no obstante derivar de la letra de cambio, no tiene la eficacia ni la naturaleza ejecutiva de las acciones cambiarias, contrariando así el principio general de que toda acción participa de la naturaleza del derecho que se invoca. Esto sucede con la acción causal [...] y la acción de enriquecimiento..."

Al respecto se debe señalar que las acciones cambiarias responden a una naturaleza distinta a la cambial, ya que no se originan de un documento cartular, sino de la obligación primitiva, en otras palabras, el origen que motivó la emisión del título valor, estos pueden ser: contrato de compra venta, obligación de dar suma de dinero, una garantía, entre otros.

Las acciones extra cambiarias según la doctrina son: la acción causal y la acción de enriquecimiento sin causa.

\subsection{ACCIÓN CAUSAL}

José Benito sostiene que "... la causa es también aquel motivo fundamental que origina la existencia del negocio cambiario". (Ferreyra, 1960, pág. 77)

Del párrafo anterior se desprende que la acción causal se configura con la existencia del negocio jurídico, esto es la determinación de una relación jurídica relevante. Es una acción extracambiaria, ya que, no se vislumbra la relación cambiaria, sino la relación jurídica fundamental que motiva la emisión del título.

Para Quintana Ferreyra “... la causa es la relación jurídica fundamental originaria subyacente que determina a las partes al libramiento o transmisión de un título de crédito" (QUINTANA FERREYRA; citado por ESCUTI, 1988:379).

Como se puede apreciar, la acción causal es la causa originaria que determinó la transmisión del título cambiario, en otras palabras, es el contrato celebrado entre las partes, lo cual dio lugar a la emisión del documento.

4 Nueva Ley General de Títulos Valores. Congreso de la Republica. Disponible en: http://www.leyes.congreso.gob.pe/ Documentos/Leyes/27287.pdf

5 Zaida Osorio Ruiz (2001). Acciones civiles en la Ley de Títulos Valores, Idemsa. 


\subsection{ACCIÓN DE ENRIQUECIMIENTO SIN CAUSA}

"La pérdida de las acciones descritas [acciones cambiarias y acción causal] por el incumplimiento de meros requisitos formales causaría un perjuicio excesivo al tenedor, quien no podría exigir judicialmente el reembolso, enriquecería injustificadamente al sujeto cambiario que hubiera recibido y retenido el valor de la letra y empobrecería al acreedor. Estos efectos se producirían inexorablemente si el legislador no concediera al tenedor negligente que dejó perjudicar la letra un último recurso procesal para obtener el valor económico que esta incorpora. Pero este recurso existe. El tenedor de una letra perjudicada puede resarcirse de su valor ejercitando la denominada acción de enriquecimiento contra el obligado que aparezca en descubierto de su reembolso, en tanto que la letra no esté prescrita..." (Pont, 1983, pág. 620)

Del texto anteriormente citado, se puede observar que esta acción es el último recurso procesal que puede interponer aquel acreedor que ha perdido la acción cambiaria y la acción causal del título cambiario, ya que el derecho no puede amparar el enriquecimiento indebido, siempre y cuando el documento no haya prescrito.

La presente acción es una medida de protección para el acreedor de un título valor, ya que tendrá otra oportunidad de pedir tutela efectiva por la vía judicial, aduciendo la figura del enriquecimiento sin causa.

Un ejemplo podría darse en el caso que por responsabilidad del acreedor se perjudicara el título valor, lo cual implicaría la perdida de la relación cambiaria, esto quiere decir que se perdería el mérito ejecutivo.

\section{CONCLUSIONES}

Los títulos valores son documentos de carácter patrimonial, destinados a la circulación, además que cumpla con los requisitos formales y esenciales que establece la Nueva Ley general de Títulos Valores.

Las tecnologías han logrado crear nuevos títulos valores, los cuales son: bonos y acciones. Estas figuras han sido incorporadas en la Nueva Ley General de Títulos Valores, la cual establece que el documento cambiario podrá ser en soporte electrónico, a este proceso se le llama desmaterialización.

Las acciones cambiarias revisten al tenedor de exigir el cumplimiento consignado en el titulo valor, esta figura ayuda al acreedor legítimo a ir por el Proceso Único de Ejecución, el cual considero es el más eficaz y rápido, para hacer efectivo la petición del solicitante.

Las acciones extracambiarias facilitan al tenedor legítimo de reclamar tutela jurisdiccional efectiva, pero no en el Proceso Único de Ejecución, ya que se ha perdido el mérito ejecutivo, sino se realizará mediante la obligación primitiva.

Se puede concluir que el tenedor nunca perderá la facultad de reclamar la obligación primitiva, sino que dependerá a qué vía le corresponde ir, ya que nuestra legislación favorece al acreedor legítimo de cualquier abuso de derecho.

\section{REFERENCIAS BIBLIOGRÁFICAS}

- Bonfanti, M. A., \& Garrone, J. A. (1981). El Cheque. Buenos Aires: Tercera edición.

- Castañeira, P. E. (1980). Títulos de Credio.Letra de Cambio-Pagare-Factura Conformada. Argentina: Ediciones Meru S.R.L.

- Ferreyra, F. Q. (1960). El problema de la causa en los titulos de crédito y en particular en la Letra de Cambio. Caracas, Venezuela: Revista de derecho y legislacion. 
- Guzmán, O. Z. (1992). Manual de Acciones Cambiarias. Lima, Perú: Universidad de Lima.

- Humboldt, L. M. (1968). La letra de cambio en la Nueva Ley Peruana. Lima, Perú: Editorial Universo.

- Legon, F. (1981). Letra de Cambio y Pagaré. (A. Perrot, Ed.) Buenos Aires, Argentina.

- Montoya Manfredi , U. (2001). Comentarios a la ley de títulos valores. Lima: Grijley.

- Pont, M. B. (1983). Manual de Derecho Mercantil. Madrid: Editorial Tecnos S.A.

- Supino, D., \& De Semo, J. (1950). De la letra de cambio y el pagare cambiario. Del cheque. (Vol. I). (J. R. Aime, D. Viterbo de Frieder, \& S. Sentin Melendo, Trads.) Buenos Aires: Editores.

- Uría, R. (1990). Derecho Mercantil. Madrid: Ediciones Jurídicas S.A.

Fecha de recepción: 14 de setiembre de 2018

Fecha de aceptación: 30 de octubre de 2018 